Fecha de recepción: diciembre 2018 Fecha de aceptación: marzo 2019

Versión final: abril 2019

\section{Morfología de las figurillas de la cultura tolita y su aplicación al diseño textil}

Katerin Estefanía Vargas Calle *

y Diego Gustavo Betancourt Chávez ${ }^{\star *}$

Resumen: La Cultura Tolita, grupo étnico ancestral, ubicado en los territorios del Ecuador, es considerada como patrimonio cultural en saberes y conocimientos ancestrales que fueron transportados a la iconografía, baluartes que hoy en día son considerados únicos por su diseño, técnica de manufactura y representación simbólica. Para realizar el análisis icnográfico se consideran los íconos más representativos mediante la interpretación, utilizando metodologías de Erwin Panofsky (pre-iconografía, iconografía e iconología) para su análisis físico y simbólico, así como el sistema de Zadir Milla en leyes de la bipartición y tripartición armónica del espacio para desestructurar el ícono, generar módulos y crear una composición que integra los fundamentos del diseño en un patrón digital para el diseño textil.

Palabras clave: Cultura tolita, análisis iconográfico, des-estructura, diseño textil, identidad.

[Resúmenes en inglés y portugués en la página 150]

${ }^{(*)}$ Ingeniera en procesos y diseño de modas por la Universidad Técnica de Ambato. Interesada en los estudios morfológicos de culturas ancestrales del Ecuador. Actualmente afianza su profesión a través de la gestión y desarrollo de una marca de moda cultural.

${ }^{(* *)}$ Magíster en Diseño, Desarrollo e Innovación de Indumentaria de Moda. Ingeniero Textil. Profesor investigador en la Carrera de Diseño Textil e Indumentaria de la Carrera de Diseño de Modas. Ha participado como coordinador en el proyecto de investigación: "Mejoramiento del proceso de suavizado de la fibra de cabuya" de la Dirección de Investigación y Desarrollo UTA

\title{
Introducción
}

La Cultura Tolita fue un grupo étnico ancestral, ubicada en los territorios del Ecuador, en Esmeraldas y expandida hacia las fronteras de Colombia conocida como Tumaco. Es considerada como patrimonio en saberes y conocimientos ancestrales que fueron transportados en elementos morfológicos con las grandes habilidades de la orfebrería en cuanto a cerámica, metalurgia, hueso, piedra y gemas preciosas, siendo una de las culturas ancestrales en representar todo su vida, cosmovisión, religión, flora, fauna, sociedad y 
enfermedades a estos artefactos, relacionada a los rituales y ceremonias. Asimismo se caracterizó por ser una de las primeras en utilizar el platino en el mundo y en manifestar montículos artificiales conocidas como "tolas".

El diseño textil es una rama de la moda ligada al arte de los textiles, una actividad técnica y creativa, determinada a presentar cualidades estéticas y estructurales en el tejido. Al hablar del diseño textil se habla de toda la composición en hilatura, tejeduría y acabados textiles con la representación de técnicas como estampados industriales y manuales, sublimados, bordados y láser. El estudio se enfoca en fortalecer el patrimonio para la difusión cultural étnica ancestral, empleándolo a los diseños textiles, como un medio para transmitir mensajes de identidad con tendencias que estén alineadas a los esquemas de moda actual, que a su vez incentive su compra al sentirse identificado con sus raíces, y la iniciativa de promover un desarrollo social y económico al país, en el área textil, artesanal y marcas de moda.

Las herramientas para la búsqueda de información es uno de los puntos focales en la morfología de las figurillas de la Cultura Tolita, dan paso al análisis e interpretación de significados en torno a la temática, conjeturan nuevas formulaciones de conceptos simbólicos y teóricos para la fundamentación de conclusiones claras y consensuadas, que proporcionan un resultado como fruto de la investigación en el que se propone presentar los elementos morfológicos de la Cultura Tolita al diseño textil mediante técnicas de acabado industriales y manuales.

\section{Metodología}

En el analisis de interpretacion de significados de la morfología de las figurillas de la Cultura Tolita se presenta a Panofsky en su libro Estudios sobre Iconología en el que propone un metodo, para analizar la iconografía y la simbología de la percepción visual presentadas en obras de arte, imágenes fotográficas y el cine. Esta metodología implica un proceso de comprensión en el que se enfoca en la importancia de la imagen y su significado en (forma y contenido), analiza la relación que se manifiesta entre ambas y profundiza en encontrar mensajes ocultos en la imagen. Para la interpretación de una obra, según el autor, se encuentran tres categorias de estudio: preiconográfico, iconográfico e iconológico (Panofsky, 1972).

Pre iconográfico: Analiza las imágenes a simple vista, detalla las características más relevantes que pueden captar los sentidos como: ancho, alto y profundidad, composición, elementos que lo conforman o particularidades estéticas como personajes, paisajes, colores, materiales, diseño y formas. Es un método más descriptivo que interpretativo para identificar y clasificar las imágenes.

Iconográfico: Interpreta del por qué de cada representación o personaje y por qué es lo que es, sus características como singularidades; implica analizar cada uno de los elementos para recabar y encontrar mensajes o significados intrínsecos ocultos en las imágenes para dar paso al estudio de la parte simbólica de cada rasgo mostrado expuesto en un ícono.

Iconológico: Es un estudio más profundo de toda la composición, analizando el todo de un ícono, donde la forma y el contenido se juntan para encontrar una nueva connotación. 
Se busca la idea de su origen, del por qué se desarrolló y para qué, como también del pensamiento de su progenitor. Por otro lado se indaga sobre su función, saber qué representa, asimismo, se interroga si manifiesta alguna singularidad que lo aparte de un grupo en especial y si genera un cierto cambio y no evoluciona con el pasar del tiempo.

En el desarrollo creativo se emplea la metodología de Zadir Milla, según su libro la Semiótica del Diseño Andino Precolombino, en el que analiza el Trazado Armónico como una búsqueda de ordenamiento armónico del espacio. Este proceso antiguamente ayudó al hombre en la organización de los trazos simétricos, desarrolló un procedimiento de construcción proporcionada, a manera de pequeños módulos, para lograr proporciones armónicas y relaciones simbólicas entre sí. Este sistema genera la capacidad compositiva y creativa del Diseño Andino, como un sistema oculto para el desarrollo iconográfico de una composición. En la geometría del Diseño Andino toda ley de formación inicia con un cuadrado del que se derivan formaciones como rectángulo o el circulo, la equipartición del cuadrado o de un rectángulo forma una cuadrícula dividiendo al icono en pequeños módulos. Dicho sistema parte de dos leyes de formación la bipartición y la tripartición del espacio, esta ley se relaciona con la formación de la cruz cuadrada (Zadir Milla, 1990).

Ley de bipartición armónica: se produce al alternar rombos y cuadrados que se interiorizan entre sí, produciendo una malla de construcción lineal en distintas modificaciones y se representa de tres formas distintas.
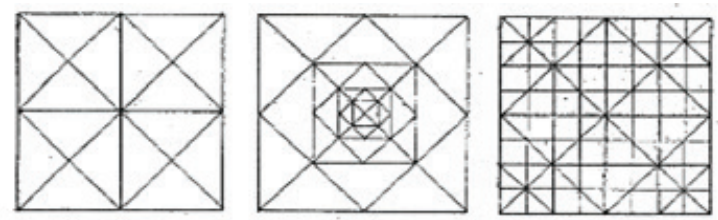

Figura No1: Ley de bipartición armónica del espacio. Fuente: Milla, 1990.

Ley de Tripartición armónica: se genera del juego de diagonales del cuadrado y el rectángulo para formas mallas con estos cruces y se representa igualmente de tres formas distintas.
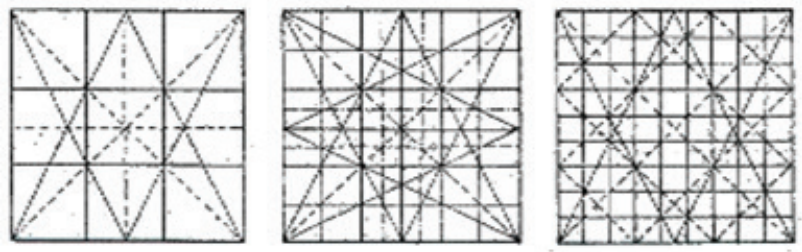

Figura No2: Ley de tripartición armónica del espacio. Fuente: Milla, 1990. 


\section{FICHA ICONOGRÁFICA}

NOMBRE: El hornbre ded pecho florido.

PERIODO: Desarrollo RegionaL.

CRONOLOGIA 600 a.C-400 d.C

REGION: Esmeraldas, La Tolíta

FUENTE: Catalogo de la sala del oro.

UBICACION: Museo Nacional del Banco Ceritral del Ecuado.

TECNICA DE MANUFACTURA: Metalurgia
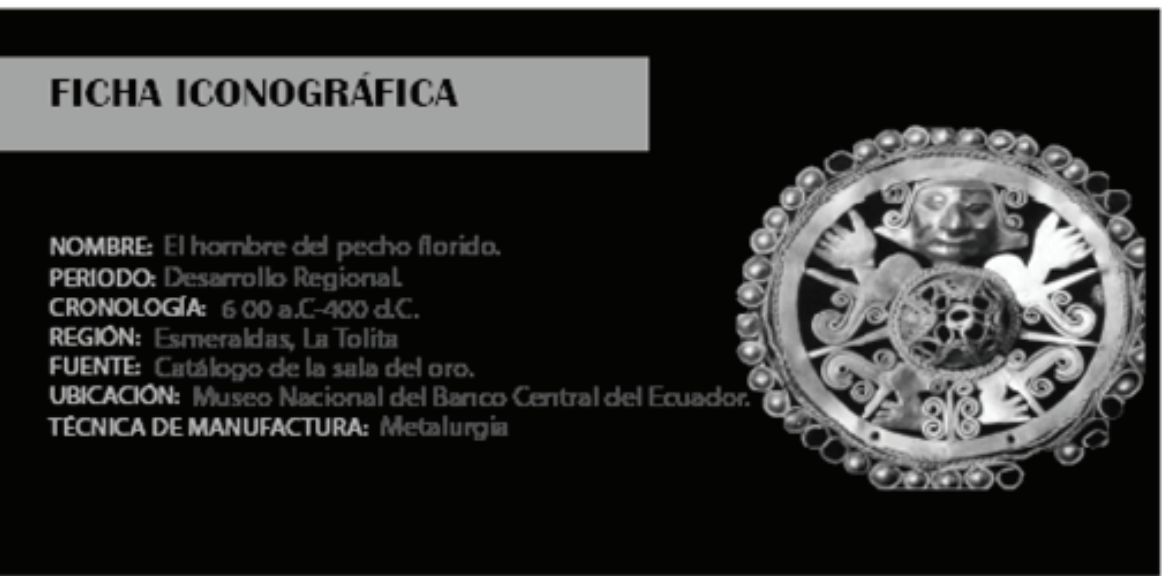

\section{PREICONOGRAFICO}

Pieza metálica con dos colores combinando el dorado y plateado, en forma circular interiorizada por un ser antropomorfa. En el centro forma una cruz con pequentos circulos sobresaliendo de la superficie en relieve. Rodeada de una fina cinta decorada del que parten una cabeza con un tocado en espirales $\mathbf{y}$ extremidades superiores e inferiores, sobresaliendo espirales $y$ en forma de $\mathrm{J}$.

Se encuentra contomeada por una lámina plana circular con una fina cinta del que resaltan pequenas volutas en todo su alrededor.

\section{Metologia de Erwin Panofsky}

\section{ICONOGRAFICO}

El metal utilizado es el oro signo de poder, es la representación del sol, fusionándolo con el platino simbolizan la nobleza.

Los espirales representan la necesidad de mantener el flujo vital de energia.

La Cruz Cuadrada simboliza su ideología y el orden del mundo en su cosmovisión.

Las formas circulares y elevadas significaban abundancia.

El ser humano es el máximo representante de la creación en la tierra.

\section{ICONOLOGICO}

Pieza decorativa utilizada como un pectoral, portado por entes de la nobleza y chamanes, como la representación del hombre en la abundancia, el orden cósmico siendo parte de su ideologla y poder

\section{Fuente:}

(Yánez, 2013)

(Ugalde, 2006)

(Matinez, 1988)

Museo de Arte Precolombino, Casa del Alabado

Figura No 3: Ficha iconográfica de "El hombre del pecho florido". Fuente: Análisis iconográfico de la figurilla 


\section{FICHA ICONOGRÁFICA}

\section{NOMBRE: Sol de la Tolita.}

PERIODO: Desarrolo Regiond.

CRONOLOGIA: $600 \mathrm{a} . \mathrm{C}-400 \mathrm{~d} . \mathrm{C}$.

REGION: Exncraldas, La Tolita.

FUENTE: Catrilogo de ha sala del oro.

UBICACON: Musco Nacional dd Banco Central ded Easador.

TECNICA DE MANUFACTURA: Metalurgin

\section{PREICONOGRAFICO}

Objeto metálico color dorado, en forma de un rostro antropomorfo rodeado de rayos en forma de serpiente

Algunos de los rayos tienen terminaciones de pequeñas cabezas trofeo, son 48 rayos.

El rostro central es de forma rectangular con la parte superior cóncava que termi na en dos proyecciones hacia arriba. Tiene orejas semicirculares con pequenas perforaciones; la nariz es prominente, en alto relieve y terminada en punta.
La forma de rayos es la representación de su Dios sol, deidad principal en sus creencias y religión.

El oro, metal precioso, signo de poder, nobleza y elite.

La serpiente simboliza la regeneración de la vida y la trasformación, utilizado como un ente de protección espiritual para caciques.

Las cabezas trofeo fueron un ritual desempenado por los habitantes de la Tolita, en la representación del enemigo caido del liderazgo y abundancia de los caciques.

\section{ICONOLOGICO}

Representa el rostro de una divinidad con rasgos humanos y de animal en forma de Sol, es una corona utilizada por personajes de mayor rango social como Caciques portado en ceremonias suntuarias y de carácter ritual simboliza la divinidad suprema de la religión de La Tolita

Fuente:

(Yănez, 2013)

(Perez, 1989)

(Matinez, 1988)

Museo de Arte Precolombino, Casa del Alabado

Figura No 4: Ficha iconográfica de "Sol de la Tolita". Fuente: Análisis iconográfico de la figurilla 


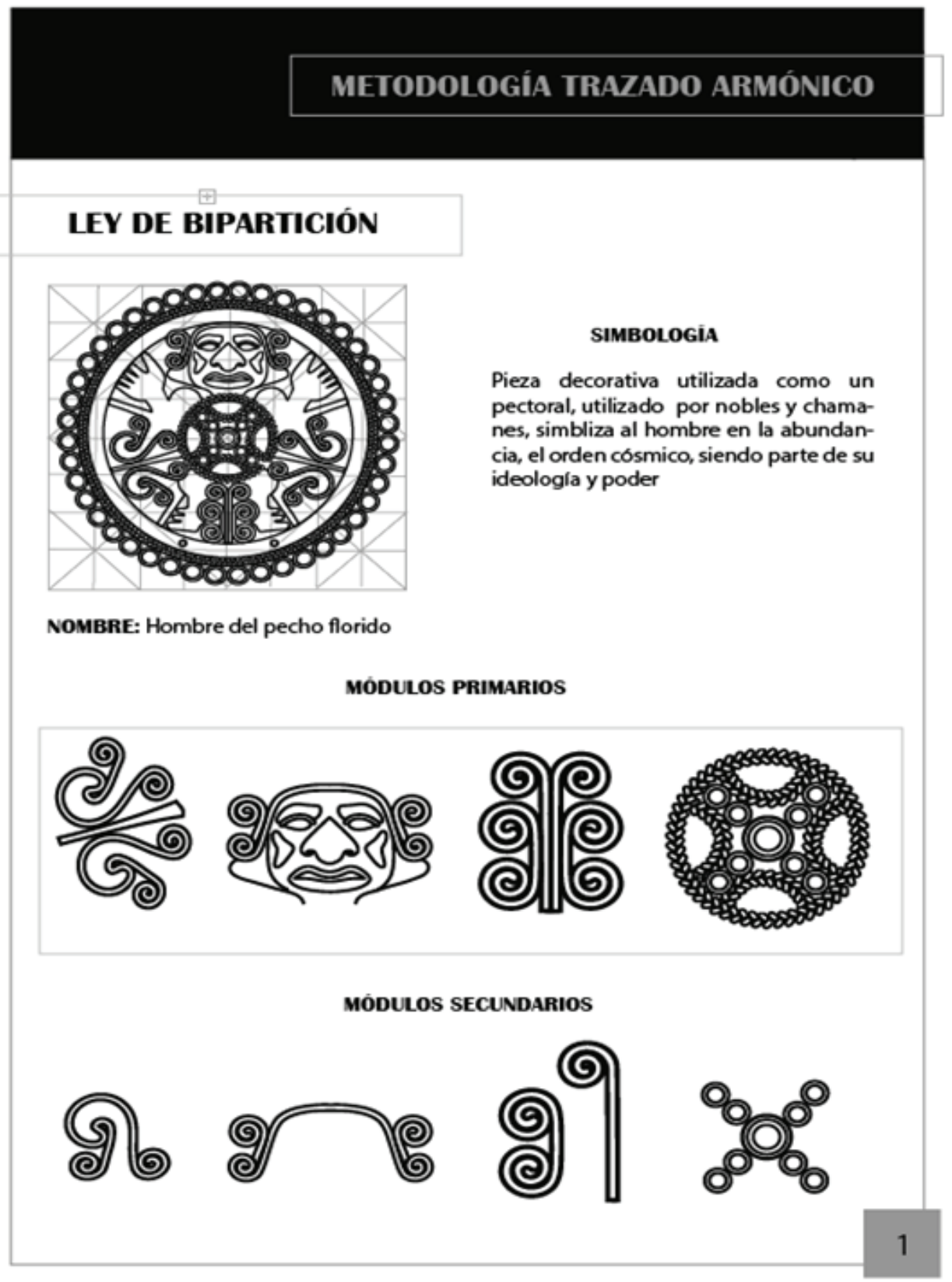

Figura No 5: Ficha Metodológica de "Hombre de pecho florido". Fuente: Análisis iconográfico de la figurilla 


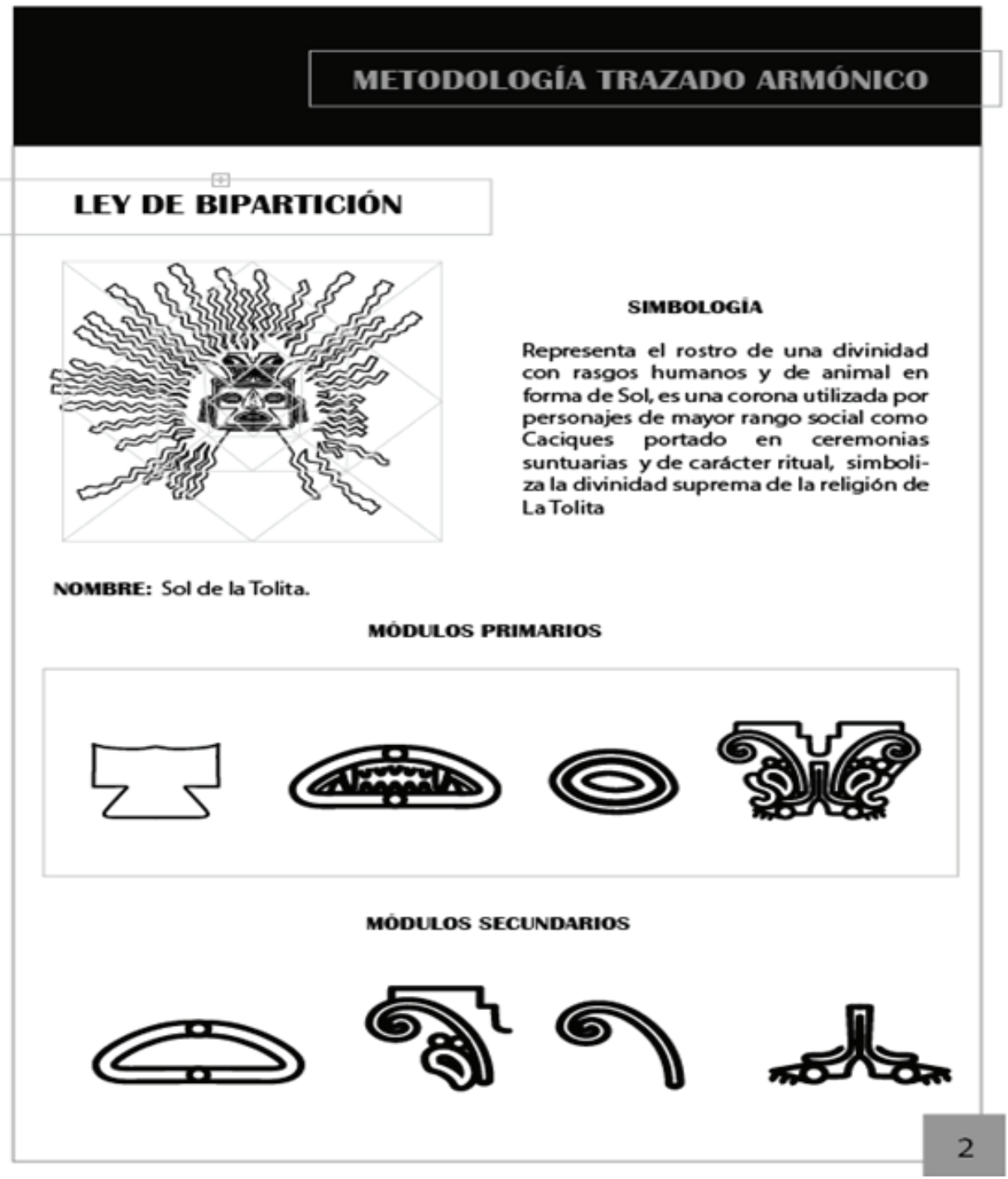

Figura No 6: Ficha metodológica de "Sol de la Tolita". Fuente: Análisis iconográfico de la figurilla 


\section{Resultados}

En resultado del análisis de la morfología de las figurillas de la Cultura Tolita se muestra la estructuración de fichas de interpretación por la metodología de Erwin Panofsky bajo los conceptos Pre - iconográfico, iconográfico e iconológico. Se muestra, además, una breve descripción del elemento morfológico como una introducción para el análisis: en el pre iconográfico se describe a simple vista los rasgos observados a simple vista de la figurilla como textura, tamaño, color y forma; en el iconográfico se busca el significado de cada parte abalado por autores que hayan conceptualizado los artefactos y; finalmente, en el iconográfico se interrelaciona todos los conceptos dados y se llega a una sola interpretación de la figurilla observada.

De la misma manera se desarrolla fichas para la metodología de Zadir Milla, en la generación de módulos al segmentar los íconos a través de las cuadrículas de las leyes de bipartición y tripartición armónica del espacio, substrayendo pequeñas formas denominándolos módulos primarios y secundarios. Se implementa los fundamentos del diseño para crear variaciones de módulos compuestos constituidos con la fusión de los elementos primarios y secundarios analizados por la metodología del trazado armónico. En la cromática de los diseños se implementa la tendencia Kinship. Finalmente se presenta un catálogo textil con los elementos morfológicos de las figurillas de la Cultura Tolita, en el que se expone los diseños textiles con las composiciones de los módulos y los diferentes acabados que se desarrolla, en diferentes gamas textiles y para diversos universos de vestuarios.

Los Textiles desarrollados en base al análisis iconográfico, cumplen con varios aspectos como, por ejemplo al analizar si este producto es aceptable o no los mismos fueron desarrollados en base a referentes que han trabajado como punto de inspiración la iconografía étnica, promoviendo así productos y marcas en las que se evidencia el uso esta relación, tanto a nivel mundial como a nivel latinoamericano especialmente en los países de América del Sur debido a que en estos países existe una mayor riqueza ancestral precolombina. Otro de los aspectos que se tomó en cuenta para la elaboración de los textiles son los usuarios a los que van direccionados los mismos, estos son los denominados la generación $\mathrm{Y}$, son personas que han crecido entre conflictos bélicos y están muy en contacto con la tecnología así como también con la comunicación digital, razón por la cual su economía es estable.

Uno de los aspectos fundamentales para el desarrollo de las propuestas de textiles es la tendencia en la cual se basó el desarrollo de los textiles la misma que es Kinship, se enfoca a las culturas y los colectivos, que a su vez tienen un buen manejo de redes sociales. De esta tendencia se desprenden formas, colores, texturas, y variados elementos.
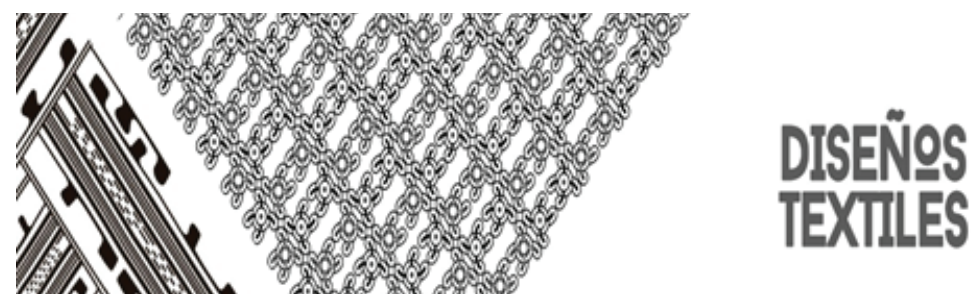

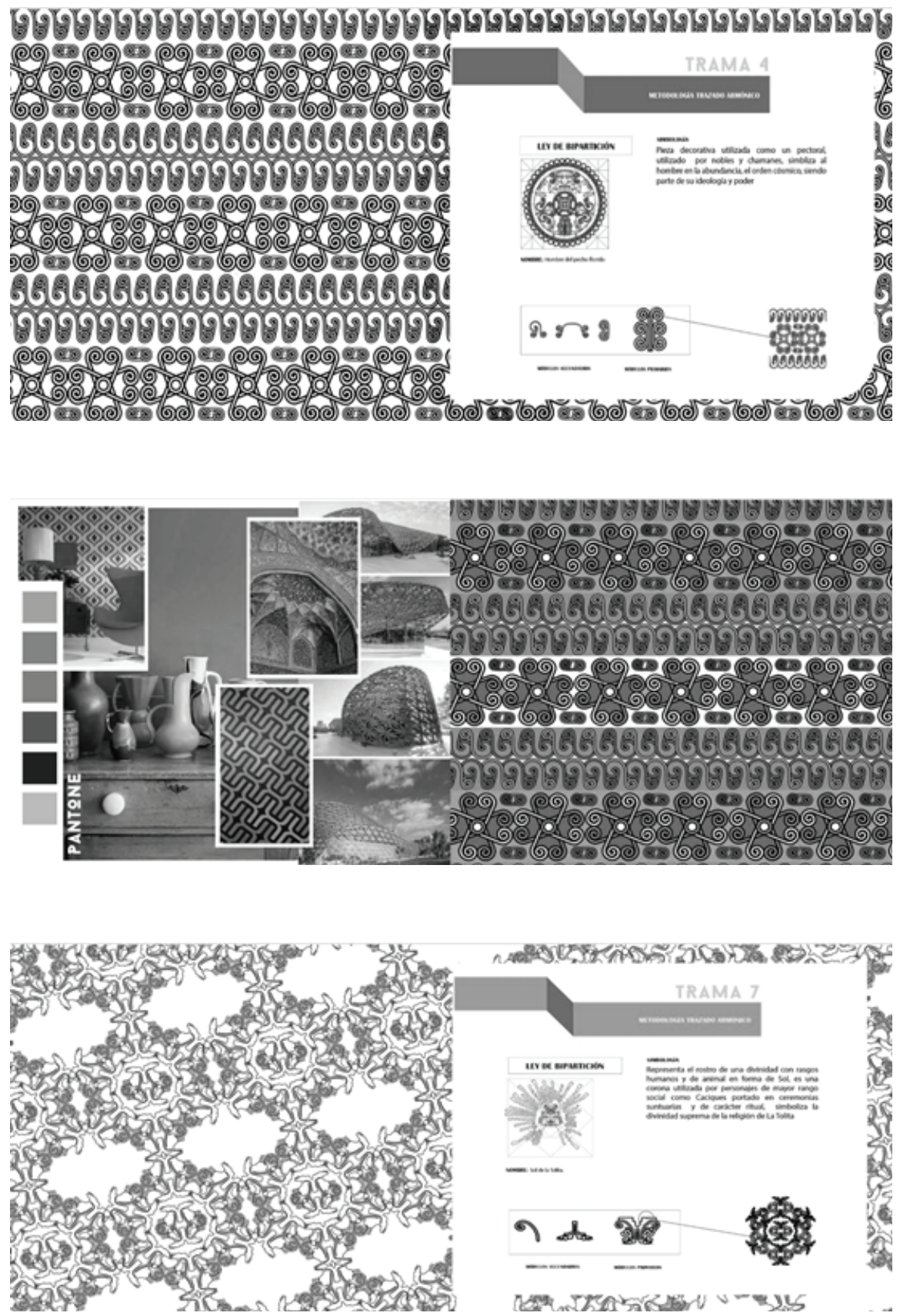

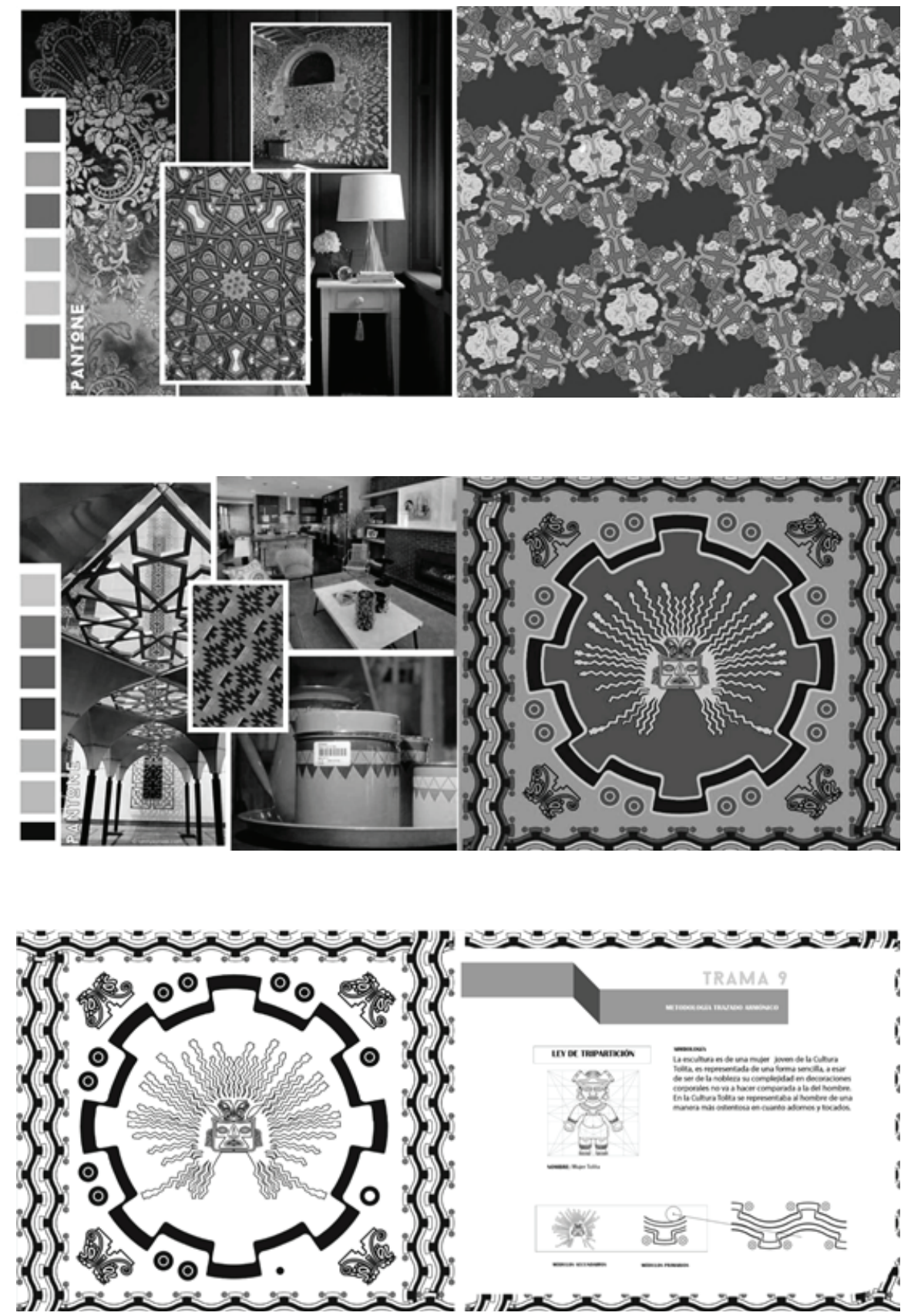


\section{Discusión}

Zeas (2006), en su tesis "Huellas del pasado", realiza un estudio investigativo del arte Precolombino desde sus inicios hasta la llegada de los colonizadores españoles al Continente Americano. Toma como inspiración la Cultura Jama Coaque que analiza geográfica como cronológicamente, estudiando la iconografía inpregnada en los sellos de esta cultura ancestral al visualizar su morfologia y simbolismos de figuras geométricas, antropomorfas, zoomorfas, fitomorfas, para transportalos estelizadamente en siete colecciones de indumentaria mediantes varias técnicas como estampadado en transfer, rodillo por láminas de aluminio, telas super puestas y cintas cosidas, tomando la iconografía como un símbolo de raíces culturales, difundido a sociedades actuales contemporaneas.

Fiadone (2014), en su libro El Diseño Indigena Argentino, analiza la iconografía o símbolos que integraron códigos destinados a prolongar el conocimiento que estuvieron plasmados en cerámica, cuero, piedra, textiles, y más representaciones simbólicas de culturas ancestrales de la Argentina como la Cultura Ciénega, La Aguada, Santa Santa María, Belén, Sanagasta, Humahuaca, Satiagueña, Wichi, Toba, Chiriguano-chané, Mapuche, Tehuelche y Ona. El objetivo es reeplantear o reconstruir los íconos, para corregir errores que fueron concebidos por el trabajo manual de los ancestros, por deformaciones causadas por el almacenamiento de estos artefactos y tambien por el tiempo en el que ha sido elaborados. La importancia es no perder la esencia de la referencia, que la replica sea igualmente a la original.

Milla (1990), plantea en su libro Semiótica del Diseño Andino Precolombino la Ley Armónica como un empleo en la forma organizacional de un elemento, partiendo del cuadrado y el rectángulo, fundamentando en dos leyes, la ley de bipartición y tripartición armónica del espacio, cada una proyectada de tres maneras diferentes para su representación, para generar módulos a partir del juego de diagonales y para relacionar a un icono y a sus elementos entre sí.

Briggs (2013), en su libro Diseño de Estampados Textiles, expone una síntesis de diseño de estampados mediante técnicas como estampado por rodillo, por sellos, láminas de acetato, en cera, serigrafía, además de las últimas técnicas utilizadas para enriquecer el textil como la impresión digital y el sublimado. Este libro está dirigido a diseñadores de moda que deseen incursionar en el mundo del diseño textil en estampados, mostrando una variedad de métodos y procesos de mercado para industrializar estampados como también el asentamiento de estos proyectos en el mundo productivo. El mencionado texto da cuenta, de este modo, de una serie de estampados de diseñadores reconocidos en la moda, exhibiendo indumentaria en desfiles y pasarelas y muestra, de una manera explicativa, el proceso de creación de un diseño textil desde un patrón diagramado digitalmente hasta el transportarte a un textil mediante técnicas de acabado.

Quinatoa E. (2013), en su trabajo Representaciones Ancestrales y Colores del Cosmos, explica el análisis de la iconografía del pueblo del Carchi en la Cultura Pastos, sus orígenes y el simbolismo de sus manisfestaciones gráficas. Presenta una colección de platos con diseños propios e involucra rasgos culturales andinos, su lenguaje auténtico, además de exponer algunas piezas originales, fortaleciendo su trayectoria mediante registros digitales de los recipientes ceramicos del Carchi. Asimismo en su investigación realza el estudio del diseño y el arte andino tanto como la procedencia física en su composición y simbología de 
cada ícono, envuelta en formas geométricas, antropomorfas y zoomorfas elaboradas con un alto sentido estético y artístico en la reinterpretación simbólica astronómica del sol, la luna, las estrellas y las constelaciones, como así también la interpretación de su calendario andino en sus solsticios y equinoccios y la influencia de la cruz cuadrada.

Las culturas ancestrales son las huellas del pasado que prevalecen en la memoria de las sociedades contemporáneas, algunos se han mantenido más fuertes que otras. Su trayectoria encaminada con manifestaciones artísticas como tecnológicas fueron el inicio de toda una esencia de tradiciones y saberes simbólicos y técnicos que en la actualidad son fuente de investigaciones como acontecimientos culturales en donde toda una sociedad se encuentra inmiscuida en la espera de propuestas identitarias que reflejen sus raíces con diseños pensados en la prevalencia de grupos culturales y su sentido en la moda. Para vestir con identidad no es necesario portar indumentos autóctonos sino productos pensados en la proyección estilística contemporánea y su difusión de entes culturales étnicos como es la Cultura Tolita en su manifestación iconográfica proyectada en el diseño textil (Quinatoa E, 2013).

El Ecuador es un país lleno de pluriculturalidad ancestral y contemporánea existente en todos los territorios con acontecimientos históricos de pueblos indígenas que dejaron su paso en el tiempo y que marcaron raíces para la conservación de estos patrimonios culturales. Su gran importancia en la prevalencia continua y futura conlleva a la realización de este proyecto para realizar una propuesta iconográfica de la Cultura Tolita analizando su historia, hallazgos y las manifestaciones artísticas que hicieron de esta cultura ancestral una de las más importantes del país y de Latinoamérica, y que fue generadora de conocimientos y saberes que dieron paso al desarrollo que hoy en día en algunas partes de Ecuador se mantiene. Por esta y por muchas razones la repercusión del proyecto prioriza en la preservación de esta sociedad antigua con la proyección de sus íconos representados en artes gráficas con acabados textiles enlazándolo con la moda en todo el campo que se conoce (Crespo, 2014).

La difusión de la innovación en la sociedad es un ancla para proyectar trabajos pensados en el campo investigativo y productivo, que no solamente se queden en el plano estético, sino también que sean capaces de emitir significados y mensajes con lo que portan. El arte gráfico de representar íconos es un tema de actualidad en el diseño, que sirve para atraer consumidores contemporáneos que están guiados por las influencia de la moda. A pesar que el proyecto está guiado por el estudio de culturas indígenas antiguas no impide que se hable también de actualidad e innovación en la propuesta. El objetivo final es este. Su enfoque se encuentra en la ejecución de acabados como sublimados, bordados, láser o técnicas utilizadas para proyectar gráficos como el estampado. Aunque se conoce que su origen se dio hace miles de años por los ancestros su técnica ha sido el conductor de nuevos proyectos actuales que trasladan este método a otras dimensiones con capacidad de presentar manifestaciones de moda con pensamiento de identidad (Raymond, 2010). El cambio ideológico que se da actualmente en la sociedad determina que estos proyectos sean parte del mundo contemporáneo, permitiendo el desarrollo de más propuestas guiadas bajo el mismo esquema. El propósito de prevalecer rasgos culturales ancestrales que impacten en el consumidor, sugiriere ideas con diseños identitarios pero, a su vez, conectados con las influencias del estilo contemporáneo. Estos iniciadores de todo un pensamiento colectivo consistente en el fortalecimiento de patrimonios ancestrales, ricos 
en arte, provocan la explosión de fuentes inspiracionales, así como también son parte de la iniciación de productos con esta corriente ideológica, que sean aptos para transformar el entorno de la sociedad. Y de esta forma, los convierte en sujetos que producen contribuyendo a la economía del país y, al mismo tiempo, en comunicadores eficaces de identidad en el plano nacional como internacional (Zúñiga, 2006).

El presente estudio está dirigido a estudiantes como profesionales Diseñadores de Moda, Diseñadores Gráficos, Ingenieros Textiles o Empresarios Textiles que encausan sus pasos en el camino de la investigación con el propósito de fortalecer la identidad cultural de país y de difundir el pensamiento ideológico de este movimiento a la sociedad, proponiendo, a su vez, nuevos productos que no solamente estén conectados con la moda, sino que sean parte de un espacio en el entorno de familias ecuatorianas. Asimismo, consideramos que este tema puede dar lugar a más investigaciones que profundicen esta problemática.

El proyecto contó con todos los recursos para la elaboración, como las fuentes bibliográficas partiendo de la investigación y también entrevistas a profesionales para abalizar y obtener información como sugerencias para la propuesta del diseño textil iconográfico con acabados textiles, en saber cuáles son los más idóneos para innovar y flexibles para proyectarlos en el textil. Además se preguntó por la experiencia de los profesionales si el producto sería factible en el mercado e indicaron que la sociedad está en la espera y ansiosos de nuevos productos que tengan el valor agregado de identidad.

\section{Listas de Referencias Bibliográficas}

Amaden, C. (2014). Fashion Sewing. Introductory Techniques. Barcelona : Bloomsbury publishing Plc.

Amadeu, F. (2017). Moda y Diseño para la Innovacion Social. Rol del Diseñador como facilitador de resilencia social, cultural, ecologica. Buenos Aires: Inti Textiles.

Amaru, J. Q. (2012). Cosmovisión Andina. Inka Pachaqaway, Lima .

Anticona, J. P. (2017). Filosofia de los Incas. Perú:. (Tesis de Grado). Facultad de Letras y Ciencias Humanas. Universidad Nacional Mayor de San Marcos.

Araoz, M. (2013). Artesania Perú, Handicrafts. Lima: Unimundo S.A.C.

Artes, C. N. (2010). Estudio de caracterización y registro de artesanias con valor cultural y patrimonial. Chile: Consejo Nacional de la Cultura y Artes.

Atapuma, P. (2017). La Tolita. Quito. (Tesis de Grado). Facultad de Comunicación Social. Universidad Central del Ecuador.

Avellaneda, D. (2012). Entre jaguares de lana y Dragones de seda, Iconografoia Textil. Buenos Aires : Nobuko.

Barrera, M. (2008). Artesanias Textiles. Salvador: Guiz.

Baugh, G. (2011). Manual de Tejidos para Diseñadores . Barcelona: Parramón Moda .

Bello, A. (2007). Artes populares latinoamericanas producciones estéticas de Chile, Bolivia y Argentina. S/C: Monografia. Mendoza.

Belting, H. (16 http://www.antropologiavisual.net/2017/que-es-la-antropologia-de-laimagen-entrevista-con-hans-belting/ de Mayo de 2017). ¿Que es la antropologia de la imagen? (C. M. Sofía., Entrevistador) 
Bravomalo, A. (2006). Ecuador Ancestral. Quito: Softpro S.A.

Brescia, C. (2015). Las cruces cuadradas Chavin y la Chakana: Arqueología e Historia. Peregrina, 17.

Briggs, A. (2013). Diseño de Estampados Textiles. Barcelona: Art Blume.

Canclini, N. G. (1977). Arte popular y sociedad en America Latina. Mexico D.F: Grijalvo, S.A. .

Capua, C. D. (2002). De la Imagen al Ícono. Estudios de Arqueología e Historia del Ecuador. Quito: Abya-Yala.

Crespo, J. M. (2014). Saberes y conocimientos ancestrales tradiicionales y populares, El buen conocer y el diálogo de saberes dentro del proyecto buen conocer. Quito: FLOK Society.

Cruz, M. (2016). Prenda Demi Couture con aplicación de telares andinos. Ambato: (Tesis de grado). Facultad de Diseño, Arquitectura y Artes. Universidad Tecnica de Ambato.

Dolmatoff, R. (1975). Chamán and the jaguar. Philadelphia: Temple University Press.

Ecuador, C. d. (2008). Asamablea Constituyente. Quito: Republica del Ecuador.

Egas, M. (2015). La cosmovisión andina se plasma en las artesanías ecuatorianas. El Telégrafo.

Escobedo, W. (2011). La Cruz Cuadrada Andina, Chakana. Cusco: .(Programa académico). Facultad de Ciencias Sociales. Universidad Andina del Cusco.

Fauria, C. (1985). El Grupo Tumaco-Tolita a través de la Colección de Torredembarra. Barcelona: Universidad de Barcelona .

Fiadone, A. E. (2014). El Diseño Indigena Argentino, Una aproximacion estetica de la iconografia precolombia. Buenos Aires: La marca editora.

Fisch, O. (1985). El Foklore que yo vivi. Quito: Cidap.

Galenao, E. (2004). Las venas abiertas de America. Coayacan: Siglo XX1 de autores, S.A de C.V .

Guamán, O. (2015). La Iconografía Precolombina y su Aplicación Artística en el Folcklor. Machala: Utmach.

Guerrero, M. Z. (2007). Joyeria de estetica etnica en base a rasgos iconograficos Salasacas. Azuay: (tesis de titulacion). Escuela de Diseño.Universidad del Azuay.

Gutiérres, A. G. (2007). Hereditas Diversitas Et Variotio, Aproximación a la historia genética humanan en Colombia. Bogotá: Fundación Cultural Javeriana de Artes Gráficas, JAVEGRAF.

Indígenas, C. N. (2005). Catálogo de Organizaciones de Artesanas y Artesanos Indígenas. Mexico: Comisión Nacional para el Desarrollo de los Pueblos Indígenas.

Inexmoda. (2012). Universos de vestuario. Bogota: ISCI.

Iwao, N. (2013). Los Tejidos Japonenes Abrigan el Mundo. Tokyo : Niponica.

Játiva, W. (2013). Guía multimedia implementada en el aula virtual como herramienta de apoyo para la enseñanza-aprendizaje de tejeduría plana. Ibarra : .(Tesis de Grado). Carrera de Ingenieria Textil. Universidad Técnica del Norte Fica.

Jimenez, A. (2009). Indigenas del Mundo Moderno, Aculturacion de las etnias mexicanas ejemplificadas por medio de los textiles. Buenos Aires: (Tesis de graduación). Facultad de Diseño y Comunicación. Universidad de Palermo.

Kendall, T. (2006). Manual para el tinte de hilos y tejios. Barcelona: Acanto.

King, E. (2003). Textile Printing, Support program for importers. Carolina del Norte: Cotton Incorporated. 
Luft, R. (2009). Artesanías Y Medio Ambiente. Mexico D.F: Comisión Nacional para el Conocimiento y uso de la Biodiversidad, Liga Periféricos- Insurgente Sur 4903.

Matínez, J. L. (1988). Artes y Joyas del Antiguo Ecuador. Chile: Museo Chileno de Arte Precolombino.

Medina, D. (2015). Consideraciones del diseño para el desarrollo de ropa jean y s relacion con la ergonomía del usuario adolescente de los colegios del cantón Patate. Ambato: .(Tesis de grado). Faculdad de Diseño, Arquitectura y Artes. Universidad Técnica de Ambato.

Mella, L. (2010). Iconografia Textil Mapuche. Santiago de Chile: .(Tesis de grado). Facultad de Arquitectura y Urbanismo. Universidad de Chile.

Milla, Z. (1990). Introduccion a la Semiotica del Diseño Andino Precolombino. Lima: Amaru Wayra.

Murra, J. (2006). Awakhuni, Tejiendo la Historia Andina. Santiago: Museo Chileno de Arte Precolombino.

Panofsky, E. (1972). Estudios sobre Iconología. Madrid: Ediciones Castilla S.A ; Maestro Alonso, 21; Madrid Printed in Spain .

Perez, G. (1989). Nuestro Pasado: La Tolita. Quito: Museo del Banco Central.

Pesok, J. (2004). Introducción a la Tecnología Textil. Montevideo: Sector Textil de la Asociacion de Ingenieros Químicos.

Polo, M. V. (2010). Plan Estratégico de Marketing para la Marca "Silvia Zeas". Cuenca: .(Tesis de Grado). Facultad de Ciencia y Tecnología. Universidad del Azuay.

Pozo, C. E. (2013). Valorizacion del paisaje cultural Andino y la arquitectura ancestral de las tolas o piramides en tierra. Quito: .Tesis de Mestria. Facultad de Artes. Universidad Central del Ecuador.

Quinatoa, E. (2013). Culturas Ancestrales del Ecuador. Quito: Ministerio de Cultura y Patrimonio.

Quinatoa, E. (2013). Representaciones ancestrales y colores del cosmos, Diseños de los platos del Carchi. Quito: Ministerio de Cultura y Patrimonio.

Quinatoa, L. (2014). Aspectos de la cosmovisión andina en la serie de kukayus pedagógicos del Sistema de Educación Intercultural Bilingüe del Ecuador en comparación con la visión occidental moderna. Quito: Titulo de Maestria. Area de Educación. Universidad Andina Simón Bolívar.

Raymond, M. (2010). Tendencias. Madrid : Promopres.

Registro Oficial, O. d. (2006). Propiedad Intelectual. Quito: Organo del Gobierno del Ecuador .

Retis, R. A. (2011). Moda étnico-andina: implicancias de su uso. Perú: .(Tesis licenciatura). Facultad de Ciencias Sociales. Universidad Mayor de San Marcos.

Rodríguez, M. (2014). Diágnostico de la producción de artesanía ancestral en los cantones Loja, Gonzanamá y Saraguro de la provincia de Loja. Loja: (Tesis de grado). Area Administrativa. Universidad Técnica Particulas de Loja.

Russell, A. (2013). Principios Basicos del Diseño Textil. Barcelona: Gustabo Guili.

Sánchez, E. (2002). Historia del artes, Arte Precolombino. Madrid : Cambio 16.

Serapio, G. (2012). Centro de Diseño Textil y Moda. Puebla: (Tesis de grado). Departamento de Arquitectura, Escuela de Artes y Humanidades. Universidad de las Américas Puebla. . 
Strano, L. (2015). Diseño de autor: partir del textil, El textil y sus invenciones. Palermo: . (Tesis de Grado). Facultad de Diseño y Comunicación. Universidad de Palermo.

Udale, J. (2008). Diseño Textil, Tejidos y Tecnicas. Barcelona: Gustavo Gili S.L.

Ugalde, M. F. (2006). Difusión en el periodo de Desarrollo Regional: algunos aspectos de la iconografía TumacoTolita. Quito: Bulletin de l'Institut français d'études andines.

Unesco. (1997). Guía metodológica para la captación de información sobre la artesanía. París: Unesco.

Unidas, N. (2015). Declaración Universal de Derechos Humanos. Ginebra: DUDH.

Yánez, J. M. (2013). Del simbolo al Diseño . Quito : Fundacion Sinchi Sacha con la cooperacion de la Union Europea .

Zapata, L. (2008). Manual práctico de curtido natural de cuero y producción de artesanías. Bolivia: Inia.

Zeas, S. (2006). Huellas del Pasado. Cuenca: .(Tesis de Grado). Facultad de Diseño. Universidad del Azuay .

Zighelboin, A. (2002). Memoria Textil e Industira del Recuerdo en los Andes. Quito: Abya Yala .

\begin{abstract}
The Tolita Culture, an ethnic group located in Ecuador, is considered as cultural heritage and ancestral knowledge that were transported to the iconography, bastions that today are considered unique for their design, manufacturing technique and symbolic representation. To perform the iconographic analysis the most representative icons are considered through interpretation, using Erwin Panofsky's methodologies (pre-iconography, iconography and iconology) for their physical and symbolic analysis, as well as the Zadir Mile's laws system that establish harmony in both bipartition and tripartition of the space to deconstruct the icon, generate modules and create a composition that integrates the fundamentals of design in a digital pattern for textile design.
\end{abstract}

Keywords: Tolita culture - iconographic analysis - de-structure - textile design - identity.

Resumo: A Cultura Tolita, um grupo étnico ancestral, localizado nos territórios do Equador, é considerada como patrimônio cultural em conhecimento e conhecimentos ancestrais que foram transportados para a iconografia, baluartes que hoje são considerados únicos por seu design, técnica de fabricação e representação simbólica. Para realizar a análise iconográfica os ícones mais representativos são considerados através da interpretação, utilizando as metodologias de Erwin Panofsky (pré-iconografia, iconografia e iconologia) para sua análise física e simbólica, bem como o sistema Zadir Milla nas leis de bipartição e tripartição harmônica do espaço para desconstruir o ícone, gerar módulos e criar uma composição que integre os fundamentos do design num padrão digital para o design têxtil.

Palavras chave: Cultura Tolita - análise iconográfica - desestrutura - design têxtil - identidade.

[Las traducciones de los abstracts fueron supervisadas por el autor de cada artículo] 